\title{
Kalender Hijriah Global Dalam Perspektif Fikih
}

\author{
Arbisora Angkat \\ Sekolah Tinggi Agama Islam Darul Arafah \\ (Email: angkatnabul@yahoo.com)
}

\begin{abstract}
Abstrak
Kalender merupakan sarana pengorganisasian waktu secara tepat dan efektif serta sebagai pencatat sejarah. Sementara bagi umat beragama khususnya umat Islam, kalender merupakan sarana penentuan hari-hari keagamaan atau ibadah secara mudah dan baik. Pada zaman dahulu, kalender berarti pertanda bagi manusia untuk melakukan hal-hal penting berkaitan dengan aktifitas ibadah maupun aktifitas sosial sehari-hari. Kalender juga merupakan pertanda dimulainya sebuah tradisi yang sudah melekat pada individu masyarakat. Dalam sejarahnya, tiap bangsa memiliki tradisi kalender dengan standar dan ciri khasnya masingmasing. Peradaban Sumeria yang muncul 6000 tahun lalu telah memiliki suatu sistem penanggalan yang terstruktur dengan baik. Bahkan di Aberdeenshire, Scotlandia, baru ini ditemukan satu bentuk kalender qamariyah tertua sejauh ini, yakni berusia mencapai hampir 10.000 tahun. Hal yang memilukan bahwa setelah hampir 15 abad usia peradaban Islam, umat Muslim tidak mempunyai satu Kalender Hijriyah Global. Tiadanya Kalender Hijriyah Global ini membawa dampak kekacauan dalam penentuan hari-hari penting keagamaan dan ibadah Islam seperti awal Ramadhan, Syawal dan Dzulhijjah. Salah satu pertemuan internasional yang baru saja dilakukan untuk melakukan penyatuan kalender hijriyah adalah sebuah muktamar bertaraf internasional di kota Istanbul, Turki. Kaidah dan rumusan Kalender Hijriyah Global ini terdapat sejumlah problematika dan dialektika, khususnya pada konsep permulaan hari, konsep awal bulan, konsep mathla'. Kalender Hijriyah Global menyisakan problem, yaitu mengenai bagaimana mengakomodir persoalan fiqh yang selama ini telah berjalan, serta mengenai landasan ilmiah, dan landasan dalil syar'inya.
\end{abstract}

Kata kunci : Kalender Hijriyah Global, Perspektif, Fiqh.

\section{A. Prolog}

Sejak awal peradaban manusia sudah merasakan perlunya sistem pembagian waktu menjadi satuansatuan periode bulan dan tahun yang lazim disebut kalender, penanggalan atau taqwim. Kebutuhan manusia akan sistem kalender itu berhubungan erat dengan kepentingan kehidupan seharihari mereka dan kepentingan kehidupan keagamaan mereka. Allah SWT berfirman dalam QS. Al-Isra' ayat 12 , yaitu :

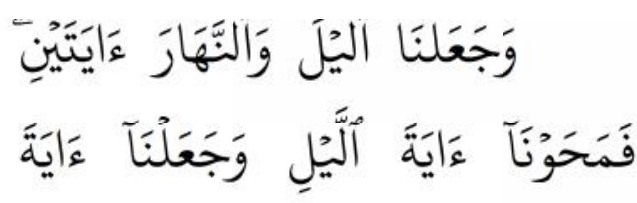

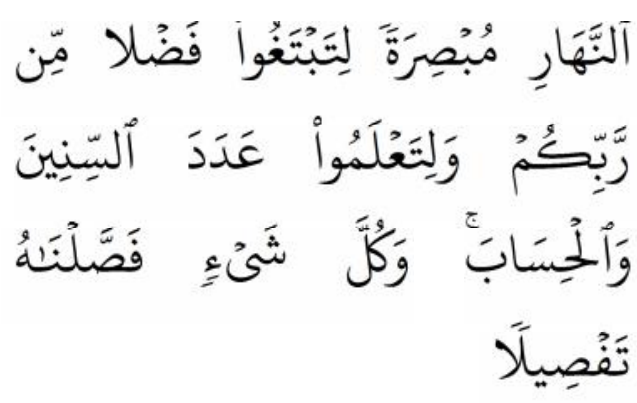

Artinya : "Dan Kami jadikan malam dan siang sebagai dua tanda, lalu Kami hapuskan tanda malam dan Kami jadikan tanda siang itu terang, agar kamu mencari karunia dari Tuhanmu, dan supaya kamu mengetahui bilangan tahun-tahun dan perhitungan. dan segala sesuatu telah Kami terangkan dengan jelas." 
Dalam ayat ini Allah menerangkan bahwa Ia menjadikan malam dan siang sebagai dua tanda kekuasaan-Nya, lalu Ia juga menerangkan bahwa Ia menghapuskan tanda malam dengan menjadikan tanda siang itu terang benderang, ayat ini dimaksudkan agar manusia dapat mencari karunia Tuhannya, dan agar manusia dapat menggali pikirannya untuk mengetahui bilangan tahun dan perhitungan waktu yang saat ini lebih terkenal dengan sebutan kalender. Acuan yang digunakan untuk menyusun kalender tersebut adalah siklus pergerakan dua benda langit yang sangat besar pengaruhnya pada kehidupan manusia di bumi, yakni bulan dan matahari. Kalender yang disusun berdasarkan siklus sinodik bulan dinamakan kalender bulan (Lunar). Kalender yang disusun berdasarkan siklus tropik matahari dinamakan kalender matahari (Solar). Sedangkan kalender yang disusun dengan mengacu kepada keduanya dinamakan kalender bulan matahari (Luni-Solar). ${ }^{1}$

Masalahnya adalah sampai saat ini belum ada keseragaman di kalangan umat Islam dunia dalam penyusunan kalender qamariyah. Sekarang tidak jarang ditemukan perbedaan tanggal qamariyah, bahkan yang lebih mencolok lagi perbedaan itu justru pada tanggal-tanggal yang langsung berkaitan dengan pelaksanaan ibadah, padahal ini adalah waktu-waktu strategis bagi umat Islam untuk melaksanakan ibadah/dakwah secara masal. Jika ibadah masal yang waktunya dilakukan dengan berbedabeda maka tentu saja akan mengurangi nilai ukhuwwah di antara umat Islam,

1 Tono Saksono, Mengompromikan Hisab Rukyat, (Jakarta : Amythas Publicita), 2007, h. 13. terutama akan kurang baik dalam pandangan umat yang beragama lain. ${ }^{2}$

Dalam Temu Pakar II untuk Pengkajian Perumusan Kalender Islam tahun 2008 di Maroko yang diselenggarakan oleh ISESCO (Islamic Educational, Scientific, and Cultural Organization (sebuah badan OKI) disimpulkan bahwa tidak mungkin mewujudkan kalender Islam unifikatif kecuali dengan menggunakan hisab sebagaimana menggunakan hisab untuk menentukan waktu-waktu shalat. $^{3}$

Bertahan pada tradisi rukyat itu memang tidak dapat disalahkan karena Nabi Muhammad Saw sendiri menegaskan, "Berpuasalah kamu karena melihat hilal dan berIdul Fitrilah karena melihatnya."4 Menurut kaidah usul fiqh, pada asasnya perintah itu menunjukkan wajib. Jadi sesuai dengan kaidah itu, melakukan rukyat itu wajib, namun yang harus disadari adalah bahwa penerapan tafsir harfiah dan tekstual seperti ini menjadi problematik pada masa kini. Di zaman Nabi Muhammad Saw memang penggunaan rukyat tidak ada masalah karena umat Islam hanya ada di

\footnotetext{
${ }^{2}$ Moedji Raharto, "Kalender Islam : Sebuah Kebutuhan dan Harapan”, Makalah disampaikan pada Seminar Nasional: Mencari Solusi Kriteria Visibilitas Hilal dan Penyatuan Kalender Islam dalam Perspektif Sains dan Syariah,Komite Penyatuan Penanggalan Islam (KPPI) Salman ITB Sabtu, 19 Desember 2009 di Kompleks Observatorium Bosscha, Lembang.

${ }^{3}$ Keputusan dan Rekomendasi "Temu Pakar II untuk Pengkajian Perumusan Kalender Islam", butir kedua pada draf awal butir ini merupakan butir pertama, kemudian setelah itu oleh Tim Perumus diperbaiki menjadi butir kedua.

4 Al-Bukhari, Sahih al-Bukhari (Beirut : Dar al-Kutub al-'Ilmiyah), 1425/2004, h. 346, Hadis no. 1909 : Muslim , Sahih Muslim (Beirut : Dar al-Fikr li atTiba'ah wa an-Nasyr wa at-Tauzi', 1412/1992), I : 482, Hadis no. 18 (1081) dan 19 (1081).
} 
kawasan dunia yang kecil, yaitu Jazirah Arab. Terlihat dan tidak terlihatnya hilal di kawasan itu tidak berdampak pada kawasan lain karena di kawasan lain itu belum ada umat Islam. Berbeda dengan zaman modern sekarang, umat Islam telah berada di seluruh penjuru bola bumi yang bulat ini. Penerapan rukyat akan membawa dampak tidak dapat menyatukan umat Islam dalam memasuki awal bulan qamariyah baru lantaran hambatan alam itu sendiri. Tafsir harfiah dan tekstual yang menjadi hambatan penyatuan kalender Islam itu harus dilampaui sebagaimana disuarakan oleh para ulama pembaharu semisal Muhammad Rasyid Rida, az-Zarqa', Yusuf al-Qardhawi, ${ }^{5}$ Ahmad Syakir, dan banyak yang lain. ${ }^{7}$

Upaya-upaya internasional untuk melakukan penyatuan kalender hijriyah telah mulai dilakukan sejak lebih dari 30 tahun lalu dan telah diadakan berbagai pertemuan internasional di berbagai belahan dunia Islam. Salah satu pertemuan internasional yang baru saja dilakukan adalah sebuah muktamar bertaraf internasional di kota Istanbul, Turki, bertitel "Mu'tamar Tauhid at-Taqwim al-Hijry ad-Dauly”(Muktamar

${ }^{5}$ Rida dkk, Hisab Bulan Qamariah : Tinjauan Syar'I tentang Penetapan Awal Ramadhan, Syawwal dan DDDzulhijjah, alih bahasa Syamsul Anwar, edisi ke-3, (Yogyakarta : Suara Muhammadiyah), 2012, Rida, Penetapan Bulan Ramadhan dan Pembahasan tentang Penggunaan Hisab, h. 87-93, Az-Zarqa', Tentang Penentuan Hilal dengan Hisab pada Zaman Sekarang, h. 95123, al-Qardhawi . Rukyat Hilal untuk Menentukan Bulan,h. 125-142.

6 Syakir, Awa'il asy-Syuhur al'Arabiyyah, (Kairo : Maktabah Ibn Taimiyah), 1407 H, cet ke-2, h. 13-16.

${ }^{7}$ Syaraf al-Qudah, "Isbat asy-Syahr al-Qamari baina al-Hadis an-Nabawi wa al'Ilm al-Hadis," makalah disajikan dalam Mu'tamar al-Imarat al-Falaki al-Awwal (Muktamar Astronomi Pertama Emirat), 13-14 Desember 2006, h. 11 dan 14.
Penyatuan Kalender Hijriyah Internasional). ${ }^{8} \quad$ Pertemuan itu dilakukan pada hari Sabtu - Senin, 2830 Mei 2016 M (21-23 Syakban 1437 H). Tuan rumah dalam penyelenggaraan kongres ini adalah "Diyanet Isleri Baskanligi" yaitu sebuah Badan Urusan Agama Turki. Muktamar ini juga merupakan kolaborasi kerjasama antara "European Council for Fatwa and Research" (ECER) yang berkedudukan di Dublin Irlandia, "Kandili Rasathanesive Deprem Arastirma Entitusu" (Observatorium Kandili dan Institut Penelitian Gempa Bumi), dan "Islamic Crescents Observation Project" (ICOP). Kongres ini sendiri dihadiri oleh perwakilan 60 negara di dunia yang terdiri dari unsur kementrian agama, instansi pemerintah, ormas, fukaha, dan astronom. Indonesia sendiri diwakili oleh tiga orang utusan yang masing-masing mewakili dan merepresentasikan Nahdlatul Ulama (NU), Muhammadiyah, dan Majelis Ulama Indonesia (MUI).

Materi persoalan yang dibicarakan sekaligus diperdebatkan dalam muktamar internasional ini adalah menyangkut bentuk kalender Islam yang akan disepakati dan diputuskan yaitu apakah kalender yang bersifat tunggal (uhady) yaitu kalender yang berlaku dan mencakup seluruh dunia (global) ataukah kalender yang bersifat bizonal (tsuna'iy) yaitu kalender yang membagi belahan bumi menjadi dua zona penanggalan atau lebih. Berbagai sumber informasi menyebutkan (khususnya informasi serta muktamar dari Indonesia) bahwa dalam pelaksanaan memang terjadi dinamika dan dialektika di kalangan pesertanya. Perdebatan tidak jauh dari apa yang selama ini diperdebatkan

\footnotetext{
${ }^{8}$ Arwin Juli Rakhmadi Butar-Butar, KALENDER ISLAM : Lokal ke Global, Problem dan Prospek, (Medan : OIF UMSU), cet. I, 2016, h. 109.
} 
yaitu masalah rukyat, masalah penerimaan hisab, masalah konsepsi awal hari, hingga masalah mathla'. Namun agaknya panitia sengaja menggiring dan memfokuskan pada perumusan penanggalan (kalender) yang bertaraf internasional-universal yaitu pada pilihan kalender tunggal atau bizonal. Setelah dialog dan debat yang panjang dan tidak ada kata sepakat di kalangan peserta, akhirnya untuk mengambil keputusan terpaksa dilakukan pemungutan suara (voting). Dalam pemungutan suara itu pada akhirnya dengan mayoritas suara hampir mutlak, kalender tunggal (uhady) memenangkan suara dominan dengan meraih 80 pendukung. Sementara kalender bizonal (tsuna'iy) memperoleh 27 suara. Sedangkan 14 suara abstain dan 6 suara rusak atau tidak sah. Dengan demikian mayoritas peserta muktamar menentukan pilihannya secara tegas bahwa kalender Islam yang akan diperlakukan secara internasional itu adalah kalender tunggal, bukan kalender bizonal. ${ }^{9}$

Kalender tunggal adalah kalender yang menjadikan bumi menjadi satu kesatuan, dimana awal bulan hijriyah di seluruh dunia dimulai secara serentak dengan hari yang sama. Prinsip fiqih yang menjadi sandaran konsep ini adalah kesatuan mutlak (ijtihad al-mathali'). Dengan kata lain, kalender putusan muktamar di Turki ini adalah kalender yang menganut prinsip "satu hari satu tanggal di seluruh dunia". Prinsip yang terakhir ini antara lain dimunculkan oleh Jamaluddin Abdur Raziq seorang

\footnotetext{
${ }^{9}$ Syamsul Anwar, PenyatuanKalender Islam Dan Keputusan Istambul : Apa Sesudahnya?,Makalah Temu Ahli Falak Muhammadiyah : Respon Atas Hasil Kongres Penyatuan Kalender Hijriyah Internasional Di Turki” (Jum'at-Sabtu, 17-18 Juni 2016/12-13 Ramadan 1437 H, diselenggarakanoleh IARN UHAMKA Jakarta). h .1
}

praktisi dan penelitian kalender Islam asal Maroko. Dalam aplikasinya kalender tunggal-global ini mengakomodir secara sekaligus kepentingan ibadah dan muamalah. Justru fungsi utama kalender hijriyah ini sejatinya adalah sebagai penjadwal terkait ibadah khususnya penentuan awal puasa dan penentuan hari Arafah. Keuntungan ditetapkannya kalender yang bersifat global ini adalah kita tidak dikhawatirkan lagi dengan adanya perbedaan dalam menetapkan hari Arafah yang sangat terkait dengan Arab Saudi.

Adapun kaidah kalender yang disahkan dalam muktamar internasional Turki ini adalah bahwa seluruh dunia dinyatakan memulai bulan baru secara serentak, apabila terjadi imkanur rukyat di belahan bumi maupun di muka bumi sebelum jam 12:00 malam (00:00 GMT/07:00 WIB) dengan ketentuan :

1. Sudut elongasi bulan-matahari pasca gurub berada pada posisi minimal $8^{0}$.

2. Tinggi bulan di atas horizon pasca gurub minimal $5^{0}$.

Selanjutnya terdapat pengecualian, yaitu apabila imkanur rukyat pertama di muka bumi terjadi setelah lewat jam 12:00 malam (00:00 GMT/07:00 WIB) maka bulan baru tetap dimulai apabila terpenuhi dua syarat berikut :

1. Imkanur rukyat memenuhi 5-8 (ketinggian hilal $5^{0}$ dan elongasi $8^{0}$ ) dantelah menjadi konjungsi sebelum waktu fajar di New Zealand yaitu kawasan paling timur di muka bumi.

2. Imkanur rukyat itu terjadi di daratan Amerika, bukan di lautan. ${ }^{10}$

Harus diakui kaidah dan rumusan kalender ini terdapat sejumlah problematika dan dialektika, khususnya pada konsepsi permulaan hari. Dari rumusan di atas tampak bahwa putusan ini menetapkan bahwa

${ }^{10}$ Ibid, h. $10-11$ 
awal hari dimulai dari tengah malam (jam 00:00) bukan pada waktu gurub (terbenam matahari) seperti diyakini dan digunakan mayoritas umat muslim di dunia selama ini. Selain itu, pilihan 5-8 itu juga menyisakan problem, yaitu mengenai landasan filosofis, landasan ilmiah, dan landasan (dalil) syar'i-nya.

Terlepas dari hal itu dalam konteks Indonesia, arti penting muktamar internasional ini adalah momentum mewujudkan persatuan dan penyatuan kalender di Indonesia. Umat Islam di Indonesia agaknya sudah lelah bahkan jenuh, berbagai dialog antar berbagai pihak yang dilakukan tak kunjung menghasilkan kata sepaham dan sepakat disebabkan faktor internal dan eksternal masing-masing pihak. Oleh karena itu kesepahaman dan kesepakatan internasional ini menjadi titik krusial penyatuan di Indonesia. Terlebih lagi bila disimak, konsepsi yang dihasilkan dalam Muktamar Internasional di Turki ini dipandang memenuhi rasa keadilan masingmasing pihak di tanah air yaitu pihak rukyat dan pihak hisab. Seperti diketahui, kalender hasil Muktamar Turki ini dalam perumusannya mendasarkan pada hisab astronomi namun tidak mengabaikan aspek rukyat dan imkanur rukyah. Terlebih penting lagi keputusan ini bernilai dan bertaraf internasional (bukan usulan personal atau komunal tertentu) sehingga sekali lagi dapat dijadikan rujukan bersama oleh semua pihak. Oleh karena itu tidak berlebihan jika Muktamar Turki ini diharapkan mampu menjadi solusi atas perbedaan yang selama ini terjadi tanpa harus menghakimi dan menegasikan pihak lain.

Di sisi lain, Kementrian Agama RI juga mengapresiasi putusan Muktamar Internasional di Turki ini. Tatkala memberi keynote speech dalam seminar nasional bertajuk "Kalender
Islam Global : Tidak Lanjut Hasil Kongres Internasional Unifikasi Kalender Hijriyah Turki 2016 Untuk Indonesia" yang diselenggarakan atas kerjasama Majelis Tarjih dan Tajdid (MTT), Pimpinan Pusat Muhammadiyah dan Islamic Science Researcd Network (ISRN), Universitas Muhammadiyah Prof Dr. Hamka (UHAMKA) Jakarta, Menteri Agama (Lukman Hakim Saifuddin) mengatakan "seminar semacam ini adalah kesempatan bagi Indonesia untuk memberikan sumbangsih pemikiran konstruktif yang dibutuhkan dalam peradaban manusia”. Betapapun pernyataan ini masih sangat umum, namun di dalamnya termuat kesan dan semangat unifikasi, bangsa Indonesia sangat mengapresiasi maksud dan tujuan muktamar ini, yaitu unifikasi kalender Islam dunia.

Dengan semua uraian tersebut di atas khusunya terkait hasil keputusan Muktamar Turki yang dihelat pada hari Sabtu - Senin, 28-30 Mei 2016 M (21-23 Syakban 1437 H), maka terdapat sejumlah pertanyaan mengenai urgensi dari sebuah Kalender Hijriyah Global, karena sampai saat ini umat Islam belum memiliki sebuah kalender hijriyah yang bersifat unifikatif. Pertanyaan selanjutnya yang muncul adalah tentang landasan fiqh Kalender Hijriyah Global, karena Kalender Hijriyah Global merupakan suatu hal yang baru. Terakhir adalah tentang bagaimana mengakomodir persoalanpersoalan fiqh yang selama ini telah berjalan apabila Kalender Hijriyah Global ini diimplementasikan.

\section{B. Urgensi Kalender Hijriyah Global}

Kehadiran kelender yang akurat dan komperhensif merupakan suatu "tuntukan peradaban" (civilization imperative), dan sekaligus merupakan 
syarat bagi suaru peradaban untuk tetap eksis dan berkembang. Pentingnya arti kehadiaran suatu kalender yang akuran dan komperhensif tidak akan mengakibatkan masyarakat kehilangan kemampuan untuk membuat perencanaan ke depan, mengelola bisnis, dan kacaunya momen-momen keragaman karena tidak adanya sistem waktu yang pasti.

Dengan ditemukannya suatu alternatif pemilihan kalender yang dapat dijadikan kalender Islam secara universal, berlaku bagi umat Islam di seluruh dunia, maka berbagai perbedaan pendapat yang terjadi di kalangan umat Islam akan dapat diantisipasi, khususnya dalam menetapkan bulan-bulan ibadah. Demikian halnya, umat Islam akan mengalami suatu standar hari, tanggal, bulan, dan tahun yang baku secara internasional, sehingga akan mempengaruhi positif dalam melakukan kegiatan sipil maupun melaksanakan ibadah keagamaan, yaitu dalam menentukan waktu-waktu ibadah akan disamakan dan diseragamkan di seluruh dunia.

Dalam praktiknya selama ini yang digunakan dalam menentukan haul adalah kalender miladiah (365 hari) dan zakatnya 2,5\%. Sebetulnya kedua kalender (miladiah dan hijriyah) dapat digunakan untuk menentukan haul. Hanya saja penggunaan masingmasing memiliki implikasi dalam kewajiban membayar prosentase zakat. Hasil penelitian Radzuan menyebutkan jika haul menggunakan kalender hijriyah maka zakatnya 2,5\%. Tetapi jika haul menggunakan kalender miladiah zakatnya $2,577 \%$
$(2.5 \times 365,25: 354,36756=2.5768 \%$ dibulatkan $=2,577 \%)$. Dengan demikian ada selisih 0,077\% (2.577\% $-2.5 \%=0.077 \%)$. Perbedaan prosentase ini disebabkan selisih hari dalam kalender miladiah dan kalender hijriyah sebanyak 11 (365 - 354) hari yang perlu diperhitungkan untuk memenuhi hak Allah. Perhatikan contoh berikut, Zakat Perniagaan yang telah ditunaikan oleh Tenaga Nasional Berhad (TNB) tahun 2007/2008 = RM 6,261 019.200, berapa zakatnya? Jawab : jika menggunakan Kalender Miladiah = RM 6,261 019.200 x 2.577 $\%=$ RM 161,346.4647. Sementara itu jika menggunakan Kalender Hijriyah $=\mathrm{RM} 6,261019.200 \times 2.5 \%=\mathrm{RM}$ $156,525.48$. Selisih pembayaran zakat menggunakan kalender miladiah dan kalender hijriyah $=$ RM 4,820.9847 (RM 161,346.4647 - $\mathrm{RM}$ 156,525.48). ${ }^{11}$

Hal di atas dikuatkan juga menurut Prof. Dr. Tono Saksono di dalam jurnalnya yang di paparkan saat menjadi seminar yang di adakan oleh Observatorium Ilmu Falak UMSU sebelum bulan Ramadhan $1436 \mathrm{H}$, beliau menyatakan bahwa jika mengeluarkan zakat menggunakan kalender masehi maka ada selisih 11.5 hari dengan kalender hijriyah. Hal ini bisa menyebabkan hutang zakat 1 tahun belum dikeluarkan jika penggunaan kalender masehi saat

11

http://museumastronomi.com/zakat-malantara-kalender-miladiyah-dan-kalenderhijriyah/ 09 september 2016, pukul 09.15 WIB. 
pembayaran zakat terus dilakukan selama kurun waktu 30 tahun. $^{12}$

Menurut mayoritas para ulama kontemporer bahwa zakat profesi tidak dikeluarkan pada saat diterima akan tetapi digabungkan dengan uang yang lain yang mencapai nishab dan mengikuti haulnya (berlalu 1 tahun Qamariyah). Pendapat ini juga merupakan hasil keputusan muktamar zakat pertama se-dunia di Kuwait pada tahun 1984, yang berbunyi, "Zakat upah, gaji dan profesi tidak dikeluarkan pada saat diterima, akan tetapi digabungkan dengan harta yang sejenis lalu dizakatkan seluruhnya pada saat cukup haul dan nishabnya". ${ }^{13}$

Akibat penggunaan kalender masehi secara konseptual dan syar'i, pembayaran zakat umat Islam dengan demikian telah mengalami defisit sekitar 3,15\% pertahun. Celakanya kesalahan ini mungkin telah berlangsung selama ratusan tahun, atau bahkan lebih dari seribu tahun. Tidak disangsikan lagi, hal ini telah membentuk bola salju hutang peradaban Islam yang telah menumpuk menjadi miliaran dolar. Hutang peadaban ini harus dihentikan jika tidak ingin mewariskan kepada anak cucu kita. ${ }^{14}$

${ }^{12}$ Tono Saksono, Mengagas Terbentuknya Islamic Calender Research Network. Pada Seminar Kalender Islam Internasional di Gd. Pascasarjana UMSU : Medan, 27 Sya'ban

${ }_{13} 1436 \mathrm{H}$, pukul $13.30 \mathrm{WIB}$.

http://syariahnya.blogspot.co.id/2013/04/pol emik-zakat-profesi.html, dipost 15:53, 13 Oktober 2016

14 Tono Saksono, Mengagas Terbentuknya Islamic Calender Research Network. Pada Seminar Kalender Islam Internasional di Gd.
Berdasarka hasil penelitian radzuan di atas dapat kita lihat bahwa jika haul yang digunakan berdasarkan kalender masehi maka persentase zakat maal yang dikeluarkan sebesar 2,58\% bukan 2,5\%, jika hal ini dilaksanakan oleh umat Islam secara terus menerus maka setiap tahunnya akan terjadi hutang zakat maal sebesar 0,08\%. Maka jika kita akumulasikan selama 33 tahun akan ada 1 tahun zakat maal yang tidak dibayarkan oleh umat Islam, hal ini lah yang akan menjadi hutang peradaban umat Islam sebagaimana yang dipaparkan oleh Prof. Tono Saksono.

Dengan merujuk sejarah masa lalu dan berikutnya memandang realita dunia hari ini dan masa depan, kiranya kehadiran Kalender Hijriyah Global dipandang teramat penting dan mendesak. Merupakan ciri agama Islam dan ajarannya yang menekankan universalitas dan globalitas, dan ini sejalan dengan esensi kehadiran Nabi Muhammad Saw sebagai rahmatan lil 'alamin. Tujuan Kalender Hijriyah Global sebenarnya adalah untuk menyatukan perbedaan umat Islam dalam menentukan awal bulan Ramadhan, Syawwal dan Zulhijjah. Penyatuan ini sendiri tidak dapat diragukan lagi merupakan syiar agama Islam yang penting. Hal ini disebutkan dalam dua firman Allah, yaitu :

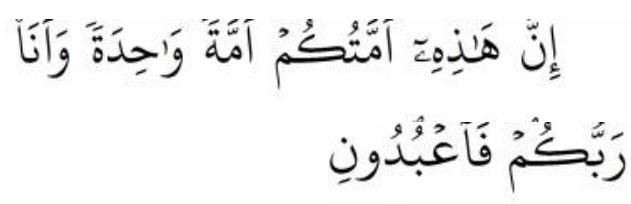

Artinya : "Sesungguhnya (agama Tauhid) ini adalah agama kamu semua, agama yang satu dan Aku adalah Tuhanmu, maka sembahlah Aku."

Pascasarjana UMSU : Medan, 27 Sya'ban $1436 \mathrm{H}$, pukul 13.30 WIB. 


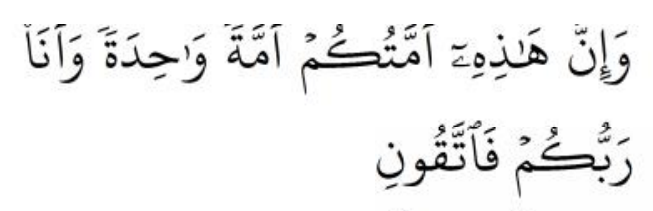

Artinya : "Sesungguhnya (agama Tauhid) ini, adalah agama kamu semua, agama yang satu, dan aku adalah Tuhanmu, Maka bertakwalah kepada-Ku."

Syiar kesatuan ini tercermin antara lain antara lain dalam iman kepada Tuhan yang satu, Al-Quran yang satu, mengikuti syariat yang satu, dan menghadap ke kiblat yang satu. Kelanjutannya adalah bahwa kita juga harus memedomani kalender yang satu (Kalender Hijriyah Global) sebagai pencerminan dari syiar tersebut.

Keharusan menerapkan kalender Hijriyah global tunggal dapat dijelaskan dari perspektif makasid syariah. Telah diketahui bahwa makasid syariah umum tujuannya adalah memberi perlindungan, pemberdayaan, dan pengembangan manusia dalam berbagai dimensi. Salah satu wujud perlindungan kepentingan manusia dalam teori makasid syariah adalah perlindungan keberagamaan ( if $a d-d \bar{\imath} n$ ). Salah satu bentuk konkret perlindungan keberagamaan itu adalah bahwa setiap orang Muslim dapat melaksanakan ibadahnya sesuai dengan waktu yang ditentukan dalam syariah untuk mengerjakannya.

\section{Landasan Fiqh Kalender Hijriyah Global}

Prinsip-prinsip Kalender Hijriyah Global sebenarnya sudah dibicarakan secara langsung dalam Alquran, seperti dalam surat At-Taubah ayat 36

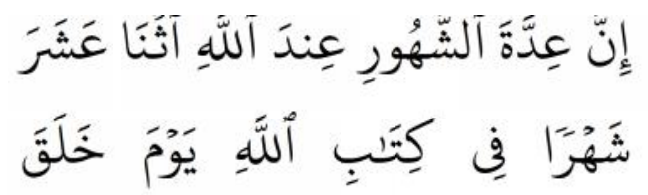

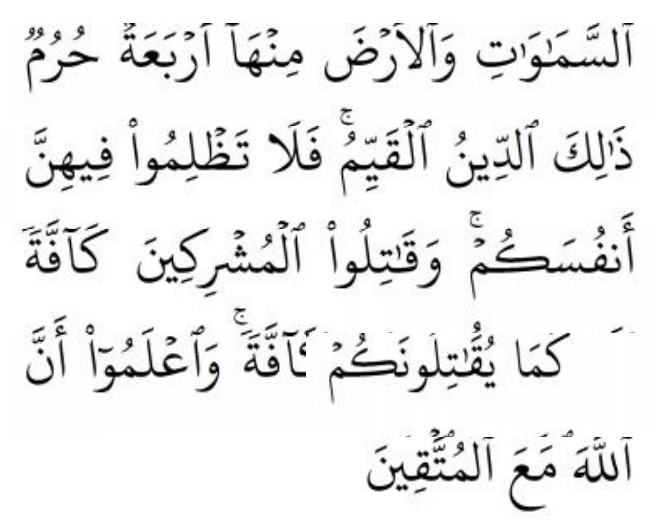

Artinya : "Sesungguhnya bilangan bulan pada sisi Allah adalah dua belas bulan, dalam ketetapan Allah di waktu Dia menciptakan langit dan bumi, di antaranya empat bulan haram. Itulah (ketetapan) agama yang lurus, Maka janganlah kamu Menganiaya diri kamu dalam bulan yang empat itu, dan perangilah kaum musyrikin itu semuanya sebagaimana merekapun memerangi kamu semuanya, dan ketahuilah bahwasanya Allah beserta orangorang yang bertakwa."

Surat Al-Taubah ayat 36 di atas berisikan informasi tentang bilangan bulan dalam satu tahun, yaitu dua belas bulan. Bulan yang dimaksud di sini adalah bulan qamariyah, karena dalam aplikasinya Allah menetapkan waktu untuk mengerjakan ibadah seperti haji, puasa, zakat menggunkana bulan-bulan qamariyah. Sedangkan dalam QS. Al-Baqarah di atas berisikan prinsip kalender hijriyah, yaitu berdasarkan pada bulan sabit.

Kemudian surat Al-Baqarah ayat 189, yaitu :

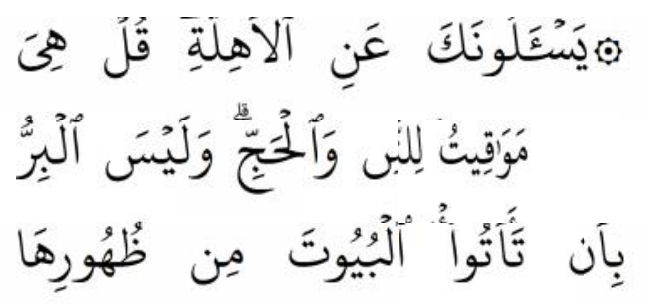




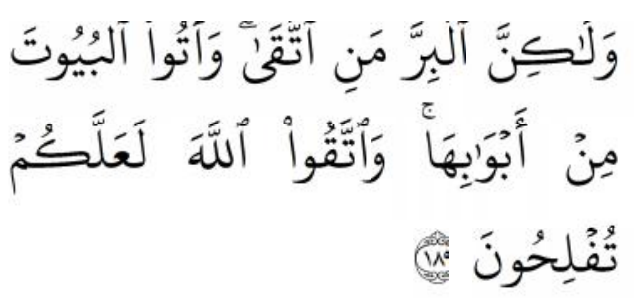

Artinya : "Mereka bertanya kepadamu tentang bulan sabit. Katakanlah: "Bulan sabit itu adalah tanda-tanda waktu bagi manusia dan (bagi ibadat) haji; dan bukan kebajikan memasuki rumah-rumah dari belakangnya, akan tetapi kebajikan itu ialah kebajikan orang yang bertakwa. dan masuklah ke rumah-rumah itu dari pintu-pintunya; dan bertakwalah kepada Allah agar kamu beruntung."

Kemudian surat Al-Kahfi ayat 25, yaitu :

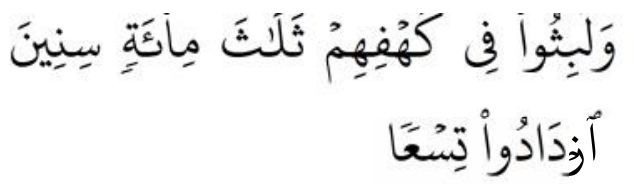

Artinya : "Dan mereka tinggal dalam gua mereka tiga ratus tahun dan ditambah sembilan tahun (lagi).”

Surat Al-Kahfi ayat 25 di atas menjelaskan perbandingkan tarikh antara kalender syamsiyah dan kalender qamariyah. Dalam ayat ini Allah menginformasikan bahwa para pemuda yang dikenal dengan ashabul kahfi tinggal dalam gua selama tiga ratus tahun ditambah sembilan tahun. M. Quraish Shihab menyatakan bahwa penambahan sembilan tahun ini adalah akibat perbedaan peanggalan syamsiah dan qamariyah. Penanggalan syamsiyah yang dikenal dengan Gregorian Calendar yang baru ditemukan pada abad ke-16 berselisih sekitar sebelas hari dengan penanggalan qamariyah. Sehingga penambahan sembilan tahun yang disebutkan dalam QS. Al-Kahfi adalah hasil perkalian 300 tahun $\times 11$ hari = 3.300 hari atau sekitar sembilan tahun lamanya.

Pendekatan hisab dan kesatuan mathla' (ijtihad al-mathali') bisa dijadikan sandaran dalam konsep Kalender Hijriyah Global. Kini ditemukan kenyataan bahwa kaveran rukyat di atas muka bumi terbatas dalam arti bahwa pada saat hilal terlihat pertama kali dari bumi, tidak semua bagian muka bumi dapat menyaksikannya. Untuk menyelesaikan masalah seperti ini dibutuhkan sebuah Kalender Hijriyah Global dimana untuk mewujudkan kalender tersebut hanya dengan menggunakan hisab. Illat perintah rukyat adalah belum adanya penguasaan hisab yang memadai. Menurut kaidah ushul fiqh :

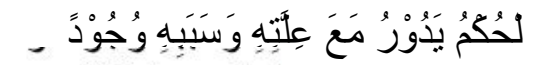
Artinya: "Hukum itu berlaku menurut ada atau tidak adanya illat dan sebabnya."

Artinya hukum berlaku, yakni rukyat digunakan, apabila ada illatnya, yaitu belum menguasai pengetahuan hisab, atau hisabnya sendiri belum memadai. Sebaliknya apabila illatnya sudah tidak ada, dalam arti pengetahuan hisab sudah banyak dikuasai, maka perintah rukyat dapat dilampaui dengan memegangi hisab demi mengatasi alam dan memungkinkan pembuatan Kalender Hijriyah Global serta dapat menyusun penanggalan jauh ke depan.

Penerapan kaidah perubahan hukum yang berbunyi,

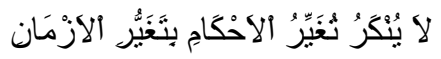

Artinya : "Tidak diingkari perubahan hukum karena perubahan zaman."

Sesuai dengan kaidah ini hukum dapat berubah. Hukum itu bisa 
berubah apabila dipenuhi empat syarat, dan syarat-syarat perubahan hukum dalam kasus rukyat sudah dipenuhi, dan karenanya perubahan dari penggunaan rukyat kepada penggunaan hisab itu sah secara syar'i untuk dilakukan. Kalender Hijriyah Global adalah kalender yang menjadikan bumi menjadi satu kesatuan, dimana awal bulan hijriyah di seluruh dunia dimulai secara serentak dengan hari yang sama.

Prinsip fiqh selanjutnya yang menjadi sandaran konsep ini adalah kesatuan mathla' (ijtihad al-mathali'). Kalender putuskan muktamar di Turki ini adalah kalender yang menganut prinsip "satu

hari satu tanggal di seluruh dunia". Hal ini sudah sesuai dengan pendapat Jumhur Ulama Mazhab Hanafi, Maliki dan Hanbali. Mereka berpendapat bahwa rukyah di suatu negeri berlaku untuk seluruh kaum muslimin di negeri-negeri yang lain, sehingga adanya perbedaan mathla' (ikhtilaf almatali') tidak memiliki pengaruh apapun terhadap penentuan masuknya bulan baru hijriyah. Pendapat ini berdasarkan pada keumuman hadis tentang perintah puasa. Hadis yang memerintahkan untuk memulai puasa ditujukan untuk seluruh umat Islam di seluruh penjuru dunia. Jika ada kesaksian hilal dapat dirukyah di satu tempat, maka kesaksian itu diberlakukan untuk seluruh umat Islam di dunia tanpa membedakan perbedaan negara dan wilayah. Perlu dicatat bahwa para ulama ini mengemukakan pendapatnya pada zaman dimana ilmu falak (astronomi) belum mencapai kemajuan seperti yang dicapainya pada zaman sekarang di satu sisi. Pada sisi lain tidak semua ulama ini menguasai ilmu falak secara cukup, kecuali Ibn Taimiyah yang memiliki wawasan luas mengenai ilmu ini.

\section{Implementasi Kalender Hijriyah Global Implementasi \\ Kalender}

Hijriyah Global menimbulkan pro dan kontra khususnya di Indonesia. Mereka yang kontra beranggapan Kalender Hijriyah Global berpotensi merenggut kedudukan hilal dari unsur lokalitas. Dengan kata lain mengambil contoh di Indonesia, dapat terjadi situasi dimana awal bulan qamariyah menurut Kalender Hijriyah Global berlangsung meski bulan masih ada dibawah ufuk. Hal tersebut dapat dilihat dalam contoh berikut $:^{15}$

\footnotetext{
${ }^{15}$ Muh. Ma'rufin Sudibyo, Bulan Sabit Tidak Di Kaki Langit : Beberapa Pertanyaan Tentang (Usulan) Kalender Hijriyah Persatuan Internasional, Makalah disampaikan pada Seminar Nasional Kalender Islam Global (Pasca Muktamar Turki 2016), Universitas Muhammadiyah Sumatera Utara, 3-4 Agustus 2016.
} 
Table contoh implementasi Kalender Hijriyah Global untuk tahun $2016 \mathrm{M}$ dan kedudukan bulan di Indonesia.

\begin{tabular}{|c|c|c|c|c|c|c|}
\hline \multicolumn{2}{|c|}{ Tahun \& Bulan } & \multicolumn{2}{|c|}{$\begin{array}{l}\text { Waktu Hilal Pertama } \\
\text { Kali Terlihat (GMT) }\end{array}$} & \multicolumn{2}{|c|}{$\begin{array}{c}\text { Awal Bulan } \\
\text { Kalender Hijriyah } \\
\text { Global }\end{array}$} & \multirow{2}{*}{$\begin{array}{l}\text { Posisi Bulan } \\
\text { di Indonesia }\end{array}$} \\
\hline \multirow{9}{*}{$\stackrel{\tilde{m}}{\Xi}$} & Rab.Tsani & 10.01 .2016 & $14: 22$ & 11.01 .2016 & Senin & \\
\hline & Jum.Ula & 09.02 .2016 & $04: 28$ & 10.02 .2016 & Rabu & Atas \\
\hline & Jum.Akhir & 09.03 .2016 & $15: 38$ & 10.03 .2016 & Kamis & Atas \\
\hline & Rajab & 07.04.2016 & $23: 55$ & 08.04.2016 & Jumat & Bawah \\
\hline & Sya'ban & 07.05 .2016 & $06: 36$ & 08.05 .2016 & Minggu & Atas \\
\hline & Ramadhan & 05.06 .2016 & $13: 52$ & 06.06 .2016 & Senin & Atas \\
\hline & Syawwal & 04.07 .2016 & $23: 35$ & 05.07 .2016 & Selasa & Bawah \\
\hline & Zulqa'dah & 03.08 .2016 & $11: 50$ & 04.08 .2016 & Kamis & Atas \\
\hline & Dzulhijjah & 02.09 .2016 & $01: 38$ & 03.09 .2016 & Sabtu & Atas \\
\hline \multirow{4}{*}{$\stackrel{\infty}{\stackrel{\oplus}{ \pm}}$} & Muharram & 01.10 .2016 & $16: 22$ & 02.10 .2016 & Minggu & Atas \\
\hline & Shafar & 31.10 .2016 & $08: 12$ & 01.11 .2016 & Selasa & Atas \\
\hline & Rab.Awal & 30.11 .2016 & $02: 07$ & 30.11 .2016 & Rabu & Atas \\
\hline & Rab.Tsani & 29.12.2016 & $21: 49$ & 30.12.2016 & Jumat & Atas/Bawah \\
\hline
\end{tabular}

Terlihat bahwa sepanjang tahun $2016 \mathrm{M}$ ada tiga kesempatan dimana bulan masih berada di bawah ufuk namun berikutnya sudah masuk awal bulan qamariyah. Masing-masing pada awal Rajab $1437 \mathrm{H}$, awal Syawwal $1437 \mathrm{H}$ dan awal Rab. Tsani 1438 H. Pada awal Rab. Tsani 1438 $\mathrm{H}$, posisi bulan di Indonesia sudah berada di atas ufuk hanya untuk kawasan Indonesia bagian barat. Sementara kawasan bagian timur tidak. Hal yang paling menyedot perhatian adalah awal Syawwal karena aspek ibadahnya, yakni hari raya Idul Fitri. Dalam konteks ini, Kalender Hijriyah Global lebih berpotensi menjadi kalender sipil (muamalah) dibanding ibadah.

Problem terpelik dalam Kalender Hijriyah Global ini terletak pada bagaimana mengakomodir persoalan-persoalan fiqh yang selama ini telah berjalan. Yakni pada masalah zakat fitrah dan masalah terlihatnya hilal. Zakat fitrah merupakan zakat yang wajib ditunaikan oleh setiap Muslim dengan mengacu waqt al- 
wujub, yakni garis waktu dibebankannya kewajiban berzakat. Patokan wajib tidaknya seorang Muslim mengeluarkan atau dikeluarkan zakat fitrahnya adalah saat ghurub (terbenamnya matahari) di hari terakhir bulan Ramadhan. Mayoritas ulama fiqh dari tiga mazhab (kecuali mazhab Hanafi) berpendapat demikian. Muslim yang meninggal dunia setelah ghurub masih memiliki kewajiban dikeluarkan zakat fitrahnya. Sementara bila meninggalnya sebelum ghurub tidaklah demikian. Sebaliknya bayi yang lahir setelah ghurub tidak mengemban kewajiban zakat fitrah. Inilah salah satu alasan ghurub dijadikan patokan pergantian hari dalam kalender hijriyah.

Kalender Hijriyah Global mengambil pergantian hari sangat berbeda. Ia sepenuhnya mengadopsi prinsip kalender masehi, yakni pada pukul 00:00 waktu setempat. Dengan demikian apabila besok hari adalah Syawwal, maka menurut Kalender Hijriyah Global selang waktu di antara ghurub hingga pukul 00:00 setempat masih terkategori sebagai hari terakhir Ramadhan. Belum menjadi bagian dari 1 Syawwal. Hal ini menimbulkan problem dalam waqt al-wujub.

Di sisi lain, mengadopsi sepenuhnya prinsip pergantian hari kalender masehi menjadi hari hijriyah juga mengesankan adanya rasa inferior (rendah diri) terkait kalender. Saat ini kalender masehi menjadi kalender terpopuler. Harus di garis bawahi bahwa prinsip kalender masehi yang kita lihat pada saat ini baru dibakukan dalam waktu seabad terakhir. Tepatnya pada Konferensi Meridian Internasional 1884. Sebelum itu prinsip pergantian kalender masehi adalah pada tengah hari pukul 12:00 setempat, sebagai pendekatan dari peristiwa transit matahari yang menandai saat tengah hari. Sementara prinsip pergantian hari hijriyah semenjak masa Umar bin Khatab hingga kini tak berubah, yakni pada saat ghurub (terbenamnya matahari), kecuali mazhab Hanafi yang berpendapat pada saat fajar. Jadi mengapa kalender yang lebih tua dengan akar sejarah nan panjang justru diusulkan untuk 'tunduk' kepada kalender yang lebih muda. ${ }^{16}$

Kalender Hijriyah Global juga berpotensi menjumpai masalah dalam ranah yang sama meskipun misalnya posisi bulan di segenap permukaan bumi telah berada di atas ufuk pada saat ghurub setempat. Pokok permasalahannya ada pada kata butir kedua keputusan Kalender Hijriyah Global, yang bunyinya "Apabila terjadi imkanur rukyat di belahan bumi maupun di muka bumi sebelum jam 12:00 malam (00:00 GMT/07:00 WIB) dengan ketentuan sudut elongasi bulan-matahari pasca gurub berada pada posisi minimal $8^{0}$, dan tinggi bulan di atas horizon pasca gurub minimal $5^{0}$. Sebenarnya maksud dari kata imkanur rukyat di kalimat tersebut apakah menggunakan rukyat atau hisab ?. Jika yang dimaksud

16 Wawancara dengan Muh. Ma'rufin Sudibyo, pada hari Kamis tanggal 04 Agustus 2016, pukul 21.00 WIB, beliau merupakan salah satu pemateri pada Seminar Nasional Kalender Islam Global (Pasca Muktamar Turki 2016), yang dilaksanakan di kampus Universitas Muhammadiyah Sumatera Utara, pada tanggal 03-04 Agustus 2016, beliau aktif di Lembaga Pengkajian dan Pengembangan Ilmu Falak Rukyatul Hilal Indonesia (RHI). 
adalah rukyat hilal, maka dalam praktiknya untuk kasus Idul Fitri 1437 $\mathrm{H}$ di Indonesia, kita harus menunggu lebih dari 12 jam lamanya sebelum mendapatkan informasi apakah hilal sudah terlihat apa belum. Sebab pada Senin 04 Juli 2016 M, hilal berada di benua Amerika bagian selatan. Menunggu hingga 12 jam lebih untuk memastikan Idul Fitri atau tidak. Hal itu jelas terlalu lama dan malah menimbulkan persoalan tersendiri. Sementara jika yang dimaksud adalah hisab, hanya benua Amerika bagian selatan yang telah memenuhi persyaratan Kalender Hijriyah Global. Tetapi penggunaan hisab semata juga tetap akan mendatangkan problema mengingat sebagian umat Islam saat ini tetap memedomani penggunaan rukyat hilal sebagai penentuan awal Ramadhan dan dua hari raya.

Hasil kongres unifikasi Kalender Islam di Istanbul, Turki 2830 Mei 2016 lalu sebetulnya telah menawarkan solusi yang cantik atas kemelut umat Islam yang selalu berbeda dalam mengawali Ramadhan, Syawwal, dan Dzulhijjah. Karena kesepakatan yang hanya diambil sekitar sebulan sebelum Idul Fitri $1437 \mathrm{H}$ ini mungkin masih memerlukan sosialisasi yang lebih baik. Sebagai hasilnya, masih terdapat perbedaan dalam mengahiri Ramadhan 1437 H yang lalu. Negaranegara yang merayakan Idul Fitri $1437 \mathrm{H}$ terbagi ke dalam empat kelompok. ${ }^{17}$

\footnotetext{
${ }^{17}$ Tono Saksono, Dogma Visibilitas Hilal dan Kemelut Kalender Islam, Makalah disampaikan pada Seminar Nasional Kalender Islam Global (Pasca Muktamar Turki 2016), Universitas Muhammadiyah Sumatera Utara, 3-4 Agustus 2016.
}

1. Mengikuti Kalender Unifikasi Turki ber-Idul Fitri pada 5 Juli 2016 sebanyak 22 negara.

2. Melakukan hisab atau rukyatul hilal sendiri dan ber-Idul Fitri pada 6 Juli 2016 sebanyak 40 negara.

3. Mengikuti Saudi Arabia dan ber-Idul Fitri pada 6 Juli 2016 sebanyak 43 negara.

4. Melakukan rukyatul hilal dan ber-Idul Fitri pada 7 Juli 2016 sebanyak 2 negara.

Indonesia masuk dalam Kelompok 2 yang ber-Idul Fitri pada 6 Juli 2016. Pada kesempatan kali ini akan dicoba membuktikan bahwa penolakan gagasan Kalender Hijriyah Global seperti yang dihasilkan Kongres Turki adalah akibat dogma visibilitas hilal yang misleading. Dogma inilah yang telah mengakibatkan kemelut pada kalender Islam yang telah berlangsung ratusan tahun. Pada kesempatan kali ini juga akan dibuktikan bahwa penolakan gagasan Kalender Hijriyah Global sebetulnya adalah penolakan pada firman Allah yang sudah sangat jelas tercantum pada surat Ya Sin ayat 39, yaitu :

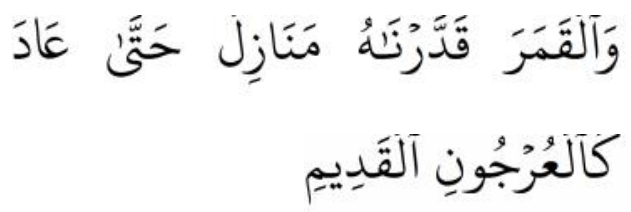

Artinya : "Dan telah Kami tetapkan bagi bulan manzilah-manzilah, sehingga (setelah Dia sampai ke manzilah yang terakhir) Kembalilah Dia sebagai bentuk tandan yang tua." Kita dapat melakukan rekapitulasi hilal yang telah Allah anugerahkan, dan hilal yang dituntut oleh umat Islam sehingga harus melakukan istikmal akibat dogma visibilitas hilal. Tabel 4 menunjukkan informasi hilal yang telah Allah anugerahkan pada umat Islam di kota Canberra, Jakarta dan Mekah. Karena kota-kota ini menolak untuk mengawali Syawwal 
1437H pada 5 Juli 2016 dan melakukan istikmal, maka pada dasarnya umat Islam di atas menuntut agar jatah keberadaan hilal diperpanjang seperti yang ditunjukkan pada Tabel-4.

Tabel 4 : Rekapitulasi umur hilal yang dianugerahkan (Allah) dan yang dituntut

\begin{tabular}{|c|c|c|}
\hline Kota & $\begin{array}{c}\text { Granted Waxing } \\
\text { Crescent (Hours) }\end{array}$ & $\begin{array}{c}\text { Demanded Waxing } \\
\text { Crescent (Hours) }\end{array}$ \\
\hline Canberra, Australia & 19 & 43 \\
\hline Jakarta, Indonesia & 23 & 47 \\
\hline Mekah, Arab Saudi & 28 & 52 \\
\hline
\end{tabular}

Silahkan direnungkan apakah betul tuntutan tersebut masuk akal ?. Tuntutan seperti itu jelas terlalu berlebihan dan merupakan bentuk keserakahan akibat dogma visibilitas hilal yang misleading. Umat Islam di Canberra menuntut agar keberadaan hilal 43 jam, umat Islam di Jakarta menuntut keberadaan hilal selama 47 jam, di Mekah menuntut keberadaan hilal selama 52 jam (lihat Tabel-4). Akibatnya, kacau balaulah kalender
Islam. Logika saintifik yang mendasari pembangunan Kalender Islam jadi diacak-acak akibat dogma visibilitas hilal ini.

Pembagian zona waktu dunia menurut kesepakatan internasional seperti pada gambar dibawah ini. Jakarta berada pada zona waktu GMT+7. Sementara Kuala Lumpur ada pada zona waktu GMT+8, dan Quito (Ecuador) berada pada zona waktu GMT-5.

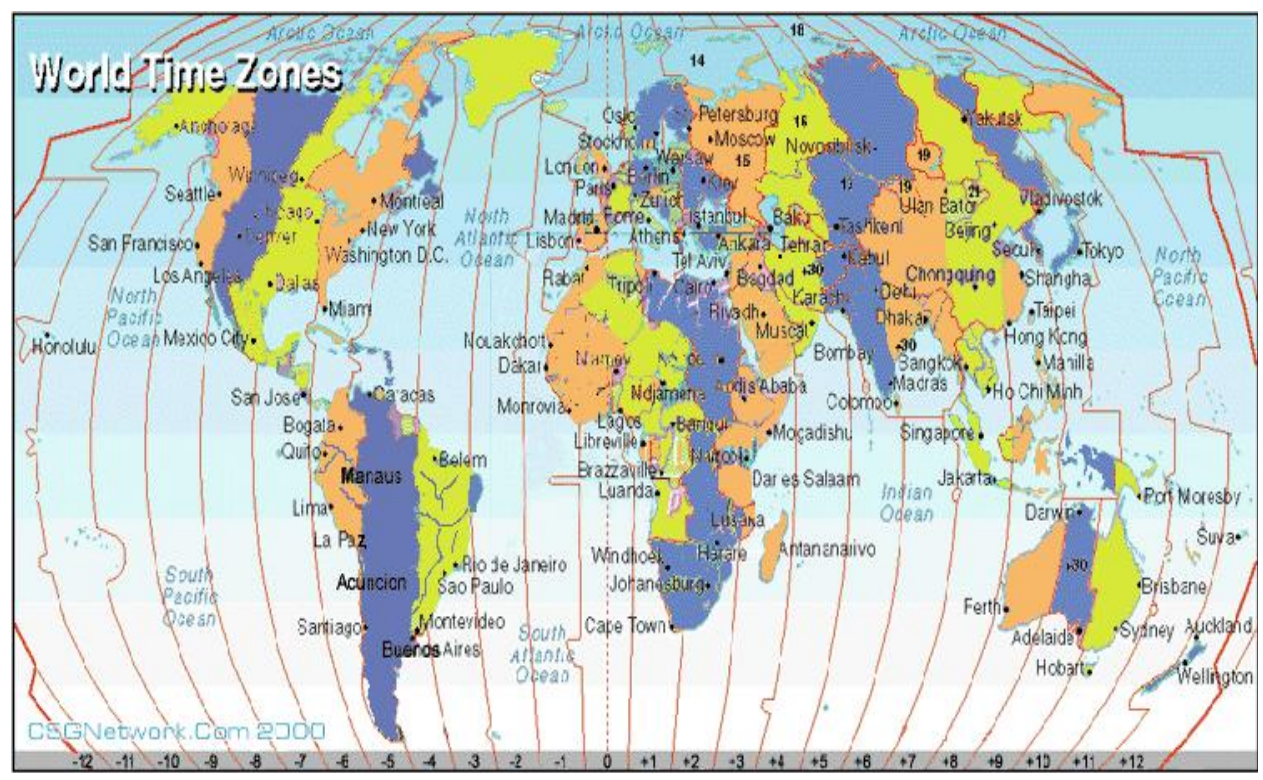

Gambar 4 : Pembagian zona waktu dunia 
Karena Jakarta berada 12 jam di depan Quito, maka saat di Jakarta tepat jam 11.00 siang tanggal $1 \mathrm{Juli}$, misalnya, di saat yang sama di Quito baru tepat jam 23:00 tanggal 30 Juni. Untuk waktu ibadah tentu saja agak sedikit berbeda. Perbedaanya tidak akan tepat 12 jam karena posisi kemiringan orbit bulan terhadap Ekliptika, koordinat (lintang, bujur) kota yang harus diperhitungkan. Saat orang Islam di Jakarta sholat maghrib jam 17:50 pada 1 Juli 2016, di Quito yang tepat 12 jam di belakang Jakarta baru jam 5:30 pagi tanggal 1 Juli 2016. Sedangkan maghrib pada 1 Juli 2016 di Quito baru akan terjadi pada jam 18:21. Sekitar 12 jam 51 menit kemudian. Jadi, itulah gambaran umumnya. Muslim di Jakarta dan Kuala Lumpur selalu akan melakukan ibadah sekitar 12 jam lebih awal daripada Muslim yang tinggal di Quito.

Jadi, jika Muslim di Jakarta, Kuala Lumpur, dan Quito kita anggap hanya melakukan ibadah sholat wajib lima waktu saja, maka selama satu tahun hijriyah, Muslim di Jakarta dan Kuala Lumpur akan melakukan sholat 1,775 kali dan selalu lebih dulu sekitar 12 jam daripada saudaranya, umat Islam di Quito. Jika kita memperhitungkan juga ibadah-ibadah sunnah (rawatib, qiyamullail, dhuha), maka dalam satu tahun akan lebih dari 4,000 kali umat Islam di Jakarta dan Kuala Lumpur melakukan ibadah lebih dulu sekitar 12 jam daripada umat Islam di Quito. Namun apa yang terjadi dengan Idul Fitri $1437 \mathrm{H}$ yang lalu. Umat Islam Jakarta dan Kuala Lumpur justru melakukan sholat Idul Fitrinya 12 jam lebih lambat dari Muslim di Quito. Jangan lupa bahwa ini terus berlanjut untuk sekitar sebulan. Selama sebulan itu, umat Islam di Jakarta dan Kuala Lumpur akan sholat justru sekitar 12 jam lebih lambat dari saudara mereka di Quito. Baru pada tanggal 3 Agustus
2016, dengan tiba-tiba umat Islam di Jakarta dan Kuala Lumpur sholat maghribnya berubah lagi menjadi normal. Mereka akan sholat maghrib 12 jam lebih awal lagi daripada saudaranya Muslim di Quito. Ini semua adalah kekacauan dalam kalender Islam akibat dogma visibilitas hilal yang sangat menyesatkan.

\section{Penutup}

Kalender Hijriyah Global merupakan satu-satunya solusi untuk mengatasi masalah umat Islam yang selalu berbeda dalam mengawali Ramadhan, Syawwal dan Dzulhijjah. Memang kriteria yang digunakan masih belum sempurna dan memerlukan perbaikan agar lebih sederhana, kaidah dan rumusan Kalender Hijriyah Global ini juga masih terdapat sejumlah problematika. Sebagai umat Islam harus yakin dan optimis bahwa awal bulan qamariyah, termasuk bulan-bulan ibadah, dan secara keseluruhan sistem penanggalan Islam dapat disatukan, karena dengan sikap optimisme akan membuka jalan untuk mencari solusi. Optimisme ini di dasarkan kepada suatu falsafah dasar yang diajarkan Nabi Muhammad Saw bahwa "Setiap ada penyakit pasti ada obatnya, apabila ditemukan obat penyakit yang tepat, maka penyakit itu akan sembuh dengan izin Allah." (HR. Muslim, AnNasa'i, Ahmad dan Al-Baihaqi). Ini artinya bahwa setiap ada problem tentu ada jalan keluar dan pemecahannya, terutama pula halnya dengan awal bulan qamariyah.

Dibutuhkan sebuah "kesepakatan bersama" untuk membuat sebuah kalender hijriyah yang dapat diberlakukan di dunia khususnya Indonesia yang memiliki kekuatan yang memaksa pada seluruh atau sebagian besar umat Islam di 
dunia khususnya di Indonesia. Kesepakatan tersebut harus didasarkan pada pertimbangan-pertimbangan ilmiah dan normatif sehingga kesepakatan bersama tersebut bukan sekedar kesepakatan yang didasarkan pada pertimbangan politis, akan tetapi juga memiliki landasan ilmiah. Di sisi lain, Kalender Hijriyah Global patut diapresiasi sebagai upaya membentuk kalender tunggal di antara umat Islam di seluruh dunia. Kajian lebih lanjut dan pencarian solusi terhadap persoalan yang mengemuka akan membuat Kalender Hijriyah Global menjadi lebih kokoh pondasinya dan dapat diterima oleh seluruh umat Islam di dunia khususnya Indonesia.

\section{Daftar Pustaka}

Al-Bukhari, Sahih al-Bukhari (Beirut : Dar al-Kutub al-'Ilmiyah), 1425/2004, h. 346, Hadis no. 1909 : Muslim , Sahih Muslim (Beirut : Dar al-Fikr li at-Tiba'ah wa an-Nasyr wa at-Tauzi', His 1412/1992), I : 482, Hadis no. $18^{\text {Pub }}$ (1081) dan 19 (1081).

Anwar, Syamsul, PenyatuanKalender Islam Dan Keputusan Istambul : Apa Sesudahnya?,Makalah Temu Ahli Falak Muhammadiyah : Respon Atas Hasil Kongres Penyatuan Kalender Hijriyah Internasional Di Turki" (Jum'at-Sabtu, 17-18 Juni 2016/12-13 Ramadan $1437 \quad H$, diselenggarakanoleh IARN UHAMKA Jakarta).

Butar-Butar, Arwin Juli Rakhmadi, KALENDER ISLAM : Lokal ke Global, Problem dan Prospek, (Medan : OIF UMSU), cet. I, 2016.

Keputusan dan Rekomendasi "Temu Pakar II untuk Pengkajian Perumusan Kalender Islam”, butir kedua pada draf awal butir ini merupakan butir pertama, kemudian setelah itu oleh Tim Perumus diperbaiki menjadi butir kedua.
Raharto, Moedji, "Kalender Islam : Sebuah Kebutuhan dan Harapan", Makalah disampaikan pada Seminar Nasional: Mencari Solusi Kriteria Visibilitas Hilal dan Penyatuan Kalender Islam dalam Perspektif Sains dan Syariah,Komite Penyatuan Penanggalan Islam (KPPI) Salman ITB Sabtu, 19 Desember 2009 di Kompleks Observatorium Bosscha, Lembang.

Rida dkk, Hisab Bulan Qamariah : Tinjauan Syar'I tentang Penetapan Awal Ramadhan, Syawwal dan DDDzulhijjah, alih bahasa Syamsul Anwar, edisi ke-3, (Yogyakarta : Suara Muhammadiyah), 2012, Rida, Penetapan Bulan Ramadhan dan Pembahasan tentang Penggunaan Hisab, h. 87-93, Az-Zarqa', Tentang Penentuan Hilal dengan Hisab pada Zaman Sekarang, h. 95-123, alQardhawi . Rukyat Hilal untuk Menentukan Bulan.

Saksono, Tono, Mengompromikan Hisab Rukyat, (Jakarta: Amythas licita), 2007.

Terbentuknya,$\quad$ Islamic $\begin{array}{r}\text { Mengagas } \\ \text { Calender }\end{array}$ Research Network. Pada Seminar Kalender Islam Internasional di Gd. Pascasarjana UMSU : Medan, 27 Sya'ban 1436 H, pukul 13.30 WIB.

—, Dogma Visibilitas Hilal dan Kemelut Kalender Islam, Makalah disampaikan pada Seminar Nasional Kalender Islam Global (Pasca Muktamar Turki 2016), Universitas Muhammadiyah Sumatera Utara, 3-4 Agustus 2016.

Sudibyo, Muh. Ma'rufin, Bulan Sabit Tidak Di Kaki Langit : Beberapa Pertanyaan Tentang (Usulan) Kalender Hijriyah Persatuan Internasional, Makalah disampaikan pada Seminar Nasional Kalender Islam Global (Pasca Muktamar Turki 2016), Universitas Muhammadiyah Sumatera Utara, 3-4 Agustus 2016. 
Syakir, Awa'il asy-Syuhur al'Arabiyyah, (Kairo : Maktabah Ibn Taimiyah), $1407 \mathrm{H}$, cet ke-2.

Syaraf al-Qudah, "Isbat asy-Syahr alQamari baina al-Hadis an-Nabawi wa
al-'Ilm al-Hadis," makalah disajikan dalam Mu'tamar al-Imarat al-Falaki al-Awwal (Muktamar Astronomi Pertama Emirat), 13-14 Desember 2006. 